patients changed from propranolol to oxprenolol, six had an improvement in their symptoms, in two they remained static, and two experienced a burning sensation in the digits. Four of the six patients whose symptoms improved regained a previously impalpable foot pulse.

In two patients given a single $80-\mathrm{mg}$ dose of propranolol the skin temperature fell by 9 and $3.5 \mathrm{C}$ respectively, but after $80 \mathrm{mg}$ oxprenolol it did not change by more than $1 \mathrm{C}$ in either case. The skin temperature began to fall about 45 minutes after the time of maximum bradycardia and was accompanied by the development of peripheral cyanosis. In the other two cases no consistent change in skin temperature was recorded after either drug.

\section{Discussion}

These results confirm the significant incidence of Raynaud's phenomenon and absent peripheral pulses associated with the use of beta-adrenergic-receptor blocking agents in hypertension. Differences in the incidence of cold hands and feet with individual agents occurred, and propranolol was implicated as being particularly apt to cause this effect.

Differences between the treatment groups were not related to their clinical characteristics. Though a degree of atheromatous vascular disease is likely to be present in hypertension, it would occur in major leg arteries and would not explain the development of cold hands after beta-blockade. The severity of the hypertension and its subsequent control were similar in both the methyldopa and beta-blockade groups. Smoking could be an additional factor, both by predisposing to atherosclerosis and by the vasoconstrictive effect of nicotine. Nevertheless, we found no association between the habit and this syndrome. The differences in durations of treatment between the groups did not match the differences in incidence of Raynaud's phenomenon, which, together with the fall in skin temperature with colour change after a single dose of propranolol, suggests that duration of treatment is not a major factor. The higher incidence of Raynaud's phenomenon in the patients taking beta-blockers compared with that in the patients on methyldopa suggests that heta-blockade is the cause.

The mechanism is still not clear. Beta-blockade reduces cardiac output, and arteriolar constriction in voluntary muscle results in decreased total limb blood flow. Possibly redistribution of blood towards surface structures together with a slow peripheral perfusion causes excessive cooling of blood. A vasoconstrictive reflex would then be stimulated to maintain the body temperature. Skin arterioles and peripheral arteries might thus constrict as a result of reflex sympathetic stimulation of alpha-receptors. Skin capillaries constrict in response to arteriolar constriction. This hypothesis is supported by the observation that skin temperature fell after beta-blockade had been established. A further contributory factor may be the increased sensitivity to alpha-receptor stimulation in peripheral blood vessels that occurs when beta-receptors are blocked. ${ }^{6}$ Thus propranolol, with its profound effects on cardiac and peripheral vasculature, caused the greatest incidence of Raynaud's phenomenon. Atenolol, being cardioselective, has a less pronounced effect on the peripheral vasculature, and oxprenolol's partial agonist activity renders it less potent both on reduction of cardiac output and in the periphery. Thus the different incidences of Raynaud's phenomenon with the three betablockers could be adequately explained. Furthermore, in two therapeutic trials of practolol, which is cardioselective and has partial agonist activity, Raynaud's phenomenon apparently did not occur ${ }^{4 ;}$

In the light of our findings we recommend that beta-blockers should be avoided in patients suffering from peripheral ischaemia. When cold hands and feet are a side effect a change of beta-blocker should be considered. It is important that future prospective trials of these agents should take full account of the incidence of this adverse effect.

\section{Referen:es}

${ }^{1}$ Hamilton, M, Thompson, E N, and Wisniewski, T K M, Lancet, 1964, 1, 235.

2 Blackwell, B, Clinical Pharmacology and Therapeutics, 1972, 13, 841.

${ }^{3}$ Zacharias, F J, Postgraduate Medical fournal, 1971, 47, suppl, p 75.

4 Prichard, B N C, Boakes, A J, and Day, G, Postgraduate Medical fournal, 1971, 47, suppl, p 84.

${ }^{5}$ Chaput de Saintonge, D M, et al, British fournal of Clinical Pharmacology, 1974, 1, 375.

${ }^{6}$ White, C de B, and Udwadia, B P, British fournal of Clinical Pharmacology, $1975,2,99$. history but with antigen A29 or AW30/31 had clinical features that distinguished them from others with valvular disease-namely, (a) isolated mitral valve disease and (b) the need for surgery, often at an early age, after a relatively short duration of symptoms.

\section{Introduction}

HLA antigens of the AW19 group are more prevalent in certain patients with acquired valvular heart disease-namely, those who, despite having chronic rheumatic heart disease, do not have a history of rheumatic fever. ${ }^{1}$ Antigens A29 and AW30/31 (members of the AW19 group) occur with the same prevalence in patients with acquired valvular disease who do have a rheumatic history as they do in control cases. Each of these antigens is significantly more common in patients with acquired valvular disease but no rheumatic history, however, than in the 
same control group ( $\chi^{2}$ test based on figures for relative incidence $=5.6$ for antigen AW30/31; for antigen A29 $\chi^{2}=8 \cdot 26$ ). One explanation for these findings might be the existence of two or more causes of acquired valvular heart disease rather than a single rheumatic aetiology. If this interpretation is correct the group of patients characterised by possession of one of the AW19 antigens might also differ in other ways from most patients with acquired valvular disease-for example, they may have distinctive clinical features.

We have examined this possibility by relating the clinical features of patients with acquired valvular disease to their HLA antigen patterns and to their past rheumatic history.

\section{Patients}

One-hundred-and-thirty-three consecutive patients attending the cardiothoracic unit, Northern General Hospital, Sheffield, as inpatients or outpatients were studied. Most had attended the unit for several years and many had previously had valve surgery. Of those seen in the wards most were either being assessed for valve surgery or were in the surgical ward awaiting operation. All patients had "chronic rheumatic heart disease"-that is, mitral stenosis, mitral stenosis and regurgitation, or combined aortic and mitral valve disease (patients with isolated aortic valve disease were excluded because of the difficulty of distinguishing clinically between congenital and acquired lesions). Valve lesions were defined initially on clinical grounds and were substantiated in most cases by findings at cardiac catheterisation and echocardiography or surgery, or both. The HLA antigen pattern of each patient was determined by a lymphocytotoxic technique using well-characterised antisera in line with the international workshop antigens. ${ }^{12}$ All patients were Caucasian. The following facts were noted: age, sex, age at onset of symptoms, valve lesions, age at operation (if done) and nature of operation. Patients were divided into three groups: group 1 consisted of patients with a history of rheumatic fever or chorea, group 2 of patients with no rheumatic history and no antigen A29 or antigen AW30/31, and group 3 of patients with no rheumatic history but antigen A29 or AW30/31.

\section{Results}

One-hundred-and-thirty-three patients with acquired valvular disease were studied. Seventy-five were placed in group 1, 44 in group 2, and 14 in group 3 (table I).

There were no significant differences between the groups or between the sexes in mean age at the time of the study, at the time of presentation, or at the time of surgery (but see below). The percentages of patients in each group requiring mitral valvotomy, mitral valve replacement, or a second operation (either mitral valvotomy or mitral valve replacement) were similar. In groups 1 and 2 a quarter of the patients were men, but $43 \%$ of group 3 were men. Various statistically significant differences are outlined below.

Aortic valve disease-In group $1,52 \%$ of patients had aortic as well as mitral valve disease compared with $21 \%$ in group $2\left(\chi^{2}=15.04\right.$; $P<0.001)$ and $7 \%$ in group $3\left(x^{2}=10.33 ; P<0.01\right)$.

Despite similar mean ages when symptoms began and when surgery was performed it was apparent that these events occurred more often at an early age in group 3 than in the other two groups. Because of this, patients in each group were divided into those who developed symptoms or who were operated on, or both, at 35 years or younger and those in whom these events occurred after the age of 35 years.

Onset of symptoms at or before the age of 35 years-In group $2,21 \%$ of patients developed symptoms before the age of 35 years compared with $39^{\circ}$ in group $1\left(\%^{2}=8.39 ; \mathrm{P}<0.01\right)$ and $50^{\circ}{ }_{0}$ in group $3\left(\chi^{2}=\right.$ $7 \cdot 2 ; \mathrm{P}<0.01$ ).

Cardiac surgery at or before the age of 35 years-In group $3,50^{\circ}$ of patients were operated on before the age of 35 years compared with $18^{\circ}$ in group $2\left(\chi^{2}=4.81 ; \mathrm{P}=0.05-0.02\right)$ and $19^{\circ}{ }_{0}$ in group 1 $\left(x^{2}=5 \cdot 29 ; P=0 \cdot 05-0 \cdot 02\right)$.

Time between onset of symptoms and operation-The differences in average times from onset of symptoms to operation between the groups were significantly different at the $5^{\circ} \%$ level (table I).

\section{Discussion}

We have suggested that the presence of HLA antigens of the AW19 group (which includes A29 and AW30/31) in patients with acquired valvular heart disease might define a subgroup of cases with a common (non-rheumatic) aetiology. Different aetiological agents would not necessarily be expected to produce obviously different valve lesions, for, irrespective of the nature of the insult, the end result is likely to be stenosis or regurgitation, or both, at the valve affected. Thus the similarity of the mitral valve lesions in the three groups defined above is not surprising and neither confirms nor refutes the view that all cases are due to previous rheumatic fever or chorea. On the other hand, patients in group 3 did have significantly less additional aortic valve disease than patients in group 1 ; in this respect group 2 appears intermediate between the other two groups.

The presence of AW19 antigens also appears to have a bearing on several factors, differences in some of which would in other diseases be suggestive evidence of different aetiologies: sex ratio, age at presentation, duration of symptoms before surgery, and the percentage of patients operated on before the age of 35 years.

TABLE II-Age at time of cardiac surgery in patients with acquired valvular heart disease

\begin{tabular}{l|c|c|c|c|c|c}
\hline Age at time of operation (years): & $\leqslant 29$ & $30-39$ & -49 & -59 & -69 \\
\hline No of patients in group 1 & $\ldots$ & 4 & 13 & 18 & 19 & \\
No of patients in group 2 & $\cdots$ & 5 & 6 & 11 & 12 & \\
No of patients in group 3 &. & 3 & 4 & 1 & 3 & 1 \\
\hline
\end{tabular}

With respect to each of these factors, group 3 patients were distinct from one or both of the other two groups which, except for age at presentation, were mutually similar. Table II shows this clearly for the age at which patients required surgery. In groups 1 and 2 more patients were operated on with each succeeding decade up to the age of 60 years. On the other hand, in group 3 fewer patients were operated on at the upper end of the age range-that is, relatively more patients in group 3 required surgery at an early age (see table I). The presence of AW 19 antigens thus defines a subgroup of patients with acquired

TABLE I-Selected clinical features in patients with acquired valvular heart disease. Mean values are given $\pm S D$

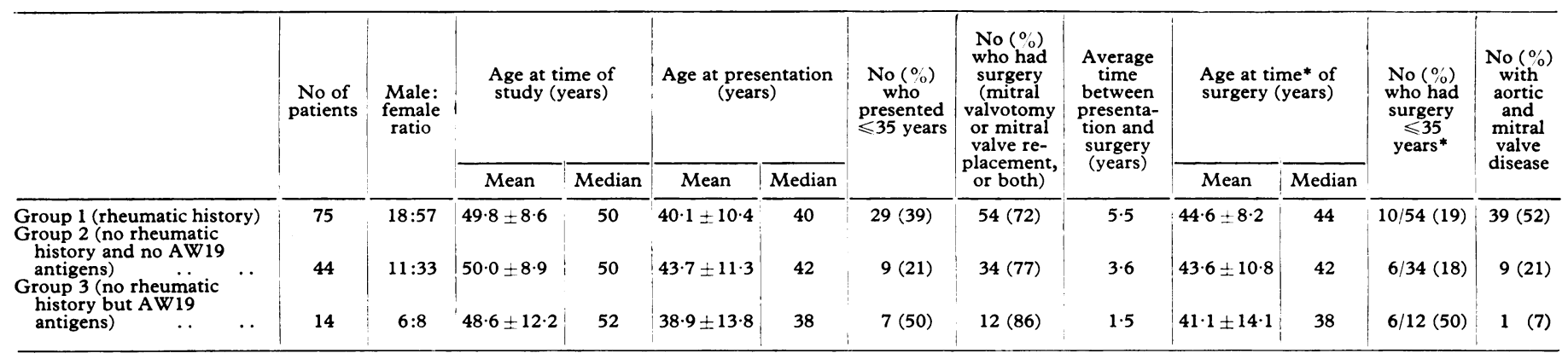

*In patients who had surgery more than once the age used for these calculations was that of their first operation. 
valvular heart disease but no rheumatic history. Generally, the main distinguishing characteristics of this subgroup are a more equal sex distribution, isolated mitral valve disease, a relatively short history of symptoms before surgery, and, in many cases, the need for surgery at a comparatively early age.

These findings are difficult to equate with the generally accepted concept of the aetiology of acquired valvular heart disease. This traditional view is that virtually all cases are rheumatic. In patients with no history of rheumatic fever or chorea their valvular disease is usually attributed to subclinical rheumatic carditis. Since it is not possible to investigate patients at the time of onset of subclinical carditis, however, the assertion that all such cases are rheumatic is speculative. It could, nevertheless, be argued for the traditional view that patients with no rheumatic history-that is, those with allegedly subclinical rheumatic carditis-differ fundamentally from those who have had classical rheumatic fever and that this may, in some way, account for clinically observed differences between those with and those without a rheumatic history. In this context the AW19 antigens might be a factor predisposing to the development of subclinical, as opposed to overt, rheumatic carditis. This line of reasoning, however, does not explain why patients with AW19 antigens differ clinically from those other patients with no rheumatic history (group 2) who are also assumed to have had subclinical rheumatic carditis.

The aetiology of these cases of valvular heart disease, if not rheumatic, is unknown. It has, however, been suggested that viruses may sometimes be implicated. In animals viruses can produce valve lesions with many of the characteristics of chronic rheumatic heart disease in man. ${ }^{3}$ There is also evidence in man that viruses ${ }^{4}$ and similar organisms ${ }^{6}$ may cause valvular damage. Other suggestions have been made which postulate a link between HLA antigens and some virus infections. For example, the neurotropism of polio virus appears to be partly dependent on the presence of HLA antigens A3 or B7. ${ }^{7}$ In more general terms it has been suggested that these particular antigens might govern the response of the central nervous system to a common product of different viruses. Possibly the cardiotropism of viruses, such as those of Coxsackie group B, which is currently unexplained, has an analogous basis. This in turn could account for the association we have described between valvular disease and the HLA antigens A29 and AW30/31-that is, these HLA antigens might act as a conditioning factor ${ }^{8}$ which occasionally transforms a mild viral myocarditis-a common occurrence ${ }^{9}-$ into a severe pancarditis.

Our study does not directly implicate viruses as a cause of acquired valvular heart disease. It does, however, provide further evidence which is inconsistent with the traditional "rheumatic" explanation. It also indicates a possible line of research into the aetiology of obscure heart disease which has not yet been explored.

We thank the physicians and surgeons of the cardiothoracic unit, Northern General Hospital, Sheffield, for allowing us access to patients under their care, and Dr I R Dunsmore, department of probability and statistics, University of Sheffield, who kindly undertook the statistical analysis of the results.

$\mathrm{CW}$ was in receipt of British Heart Foundation Research Grant No 496, and KG and RWD were in receipt of a medical research grant from the Trent Regional Health Authority.

\section{References}

1 Ward, C, et al, Tissue Antigens, in press.

${ }^{2}$ Gelsthorpe, K, and Doughty, R W, Medical Laboratory Technology, 1971, 28, 22.

3 Sun, S C, et al, British fournal of Experimental Pathology, 1967, 48, 655.

4 Sainani, G S, Krompotic, E, and Slodki, S J, Medicine, 1968, 47, 133.

${ }^{5}$ Burch, G E, and Colcolough, H L, Annals of Internal Medicine, 1969, 71, 963.

6 Ward, C, and Ward, A M, Lancet, 1974, 2, 734.

7 Morris, P J, and Pietsch, M J, Lancet, 1973, 2, 848.

${ }^{8}$ Pearce, J M, Archives of Pathology, 1939, 28, 827.

9 Verel, D, et al, British Heart fournal, 1974, 36, 395.

\title{
Cows' milk protein intolerance: a possible association with gastroenteritis, lactose intolerance, and IgA deficiency
}

\author{
MARY HARRISON, ANNE KILBY, J A WALKER-SMITH, N E FRANCE, C B S WOOD
}

British Medical fournal, 1976, 1, 1501-1504

\section{Summary}

Twenty-five children with cows' milk protein intolerance were studied. Twenty had presented with an illness clinically indistinguishable from infantile gastroenteritis; an enteropathogenic Escherichia coli was isolated from the stools in two children, and in six another member of the family simultaneously developed acute diarrhoea and vomiting. Twenty-three children had lactose intolerance

Queen Elizabeth Hospital for Children, Hackney Road, London E2 8PS

MARY HARRISON, MRCP, DCH, clinical lecturer in child health ANNE KILBY, MB, MRCP, research fellow in paediatric gastroenterology J A WALKER-SMITH, MRCP, FRACP, consultant senior lecturer N E FRANCE, MB, FRCPATH, consultant pathologist

C B S WOOD, DCH, FRCP, professor of child health secondary to cows' milk protein intolerance. Eight out of 20 children were found to be partially IgA deficient. An acute attack of gastroenteritis, in damaging the small mucosa, may act as a triggering mechanism in cows' milk protein intolerance, and a deficiency in $\operatorname{IgA}$ may be a predisposing factor in so far as it allows the patient to become sensitised to foreign protein.

\section{Introduction}

Cows' milk protein intolerance is the clinical syndrome due to sensitisation to cows' milk protein antigens. The resulting immunological reaction causes symptoms that may be predominantly gastrointestinal, respiratory, or dermatological."

Our purpose here is to report the possible role of gastroenteritis in the aetiology of cows' milk protein intolerance, describe the clinical and laboratory features of a group of children diagnosed as having the condition, and offer a hypothesis about the possible relationship between cows' milk protein intolerance, gastroenteritis, and lactose intolerance. 